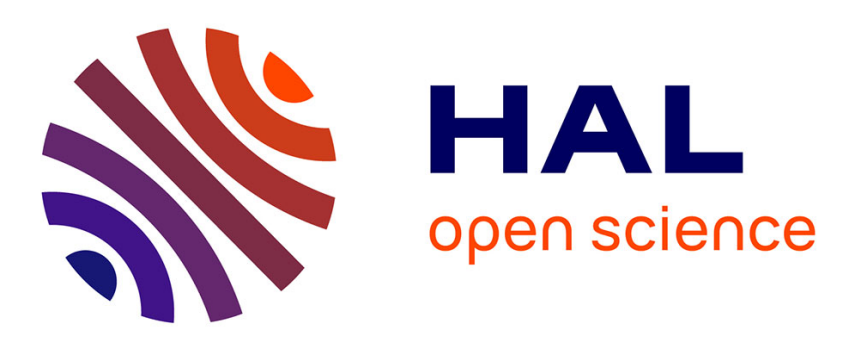

\title{
Comparison of Skin Model representations and Tooth Contact Analysis techniques for Gear tolerance analysis Jean-Yves Dantan
}

\section{To cite this version:}

Jean-Yves Dantan. Comparison of Skin Model representations and Tooth Contact Analysis techniques for Gear tolerance analysis. Journal of Computing and Information Science in Engineering, 2014, 29p. 10.1115/1.4028961 . hal-01116068

\section{HAL Id: hal-01116068 \\ https://hal.science/hal-01116068}

Submitted on 12 Feb 2015

HAL is a multi-disciplinary open access archive for the deposit and dissemination of scientific research documents, whether they are published or not. The documents may come from teaching and research institutions in France or abroad, or from public or private research centers.
L'archive ouverte pluridisciplinaire HAL, est destinée au dépôt et à la diffusion de documents scientifiques de niveau recherche, publiés ou non, émanant des établissements d'enseignement et de recherche français ou étrangers, des laboratoires publics ou privés. 


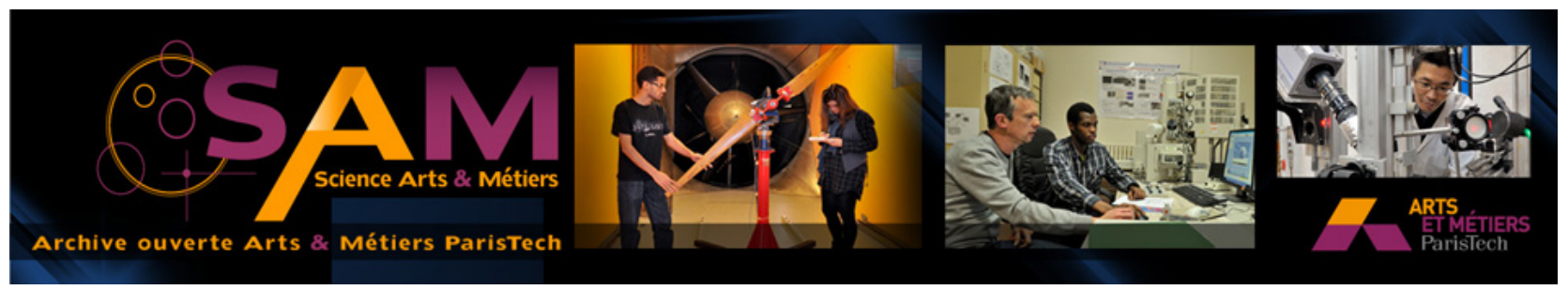

Science Arts \& Métiers (SAM)

is an open access repository that collects the work of Arts et Métiers ParisTech researchers and makes it freely available over the web where possible.

This is an author-deposited version published in: http://sam.ensam.eu

Handle ID: .http://hdl.handle.net/10985/9316

\section{To cite this version :}

Jean-Yves DANTAN - Comparison of Skin Model representations and Tooth Contact Analysis techniques for Gear tolerance analysis - Journal of Computing and Information Science in Engineering p.29p. - 2014 


\title{
Comparison of Skin Model representations and Tooth Contact Analysis techniques for Gear tolerance analysis
}

\author{
Jean-Yves DANTAN ${ }^{1}$ \\ LCFC - Arts et Métiers ParisTech \\ 4 rue $A$. Fresnel, 57078 METZ, FRANCE \\ jean-yves.dantan@ensam.eu
}

\begin{abstract}
To improve the tolerancing process in an industrial context, there exists a strong need for tolerance analysis to estimate the probability of scrap in an acceptable computer time and managing the accuracy of the results. The developed approaches for gear tolerance analysis based on simulation, depend on the type of the Skin Model representation, and on the type of behavior model. Therefore, this paper proposes a comparison of four Skin Model representations (discrete shape / parametric surface), and three Tooth Contact Analysis techniques (discrete approach / simulation of tangency of tooth surfaces) regarding accuracy of results, computation time and the adequacy with the standard tolerance practices.
\end{abstract}




\section{INTRODUCTION}

Tolerance analysis concerns the verification of the value of functional requirements after tolerance has been specified on each component. Usually, the used approach for tolerance analysis of a complex system like gear is based on experimentations or numerical simulations. In order to determine the effects of a tolerance and to understand the contributions of tolerances on the system behavior, it is necessary to identify the relationships between tolerances and functional characteristics by a set of experiments or numerical simulations.

Currently, the developed approaches depend on the type of geometrical model and on the type of system response function or simulation model (behavior model). To define the global context of this paper, we can distinguish three main issues in tolerance analysis:

1. The models for representing the geometrical deviations,

2. A mathematical model for calculating the system behavior with deviations,

3. The development of the analysis methods.

Tolerance analysis has to simulate the "real-world" of the product with the minimum of uncertainty. A part of this uncertainty is due to the model uncertainty. In fact, Daniel P. Loucks said: "The usefulness of any model depends in part on the accuracy and reliability of its output. Yet, because all models are imperfect abstractions of reality, and because precise input data are rarely if ever available, all output values are subject to imprecision." [1]. 
Therefore, this paper focuses on the comparison of models for representing the geometrical deviations (skin model representations) and on the comparison of mathematical models for calculating the system behavior (Tooth Contact Analysis techniques).

This paper is divided into three main sections. The first section presents some skin model representations of gear, the second some mathematical models for tooth contact analysis, and the last section provides a comparison of these models.

\section{SKIN MODEL REPRESENTATIONS}

The concept of Skin model was proposed by Ballu and Mathieu [2]. The skin model has been developed to enrich the nominal idealized geometry considering physical shapes. The concept stemmed from the theoretical foundations of Geometrical Product Specification (GPS). The skin model represents the interface of the part with its environment.

The representation of the skin model has been investigated only recently. A discrete shape approach is proposed by Zhang et al. [3]. Schleich et al. [4] proposed a comprehensive framework for skin model simulation.

A significant amount of research efforts has been given in the last decade to explore the fundamental, mathematical basis for geometric tolerance representation. The reported mathematical models are developed either

- $\quad$ by using the tolerance zone approach (Offset zone models, tolerance zone around theoretic geometry - Requicha [5] represents the model variations as a pair of "offset boundaries," or offset surfaces, which bound each ideal 
surface. The set of offset boundaries form a tolerance zone which bounds the entire part ),

- by using the variational geometry approach or by using other variational models (Variational models or parameterization of deviations from theoretic geometry. The real geometry of parts is apprehended by a variation of nominal dimension or it is apprehended by a variation of the nominal geometry. The principle of vectorial tolerancing [6] is based on the concept of substitute surfaces. A substitute feature is an imaginary geometrical ideal surface which is represented by parametric vectors).

Based on these concepts, we propose four skin model representations for gear:

- discrete shape,

- discrete shape with Vectorial Dimensioning and Tolerancing (VD\&T) strategy,

- parametric surface,

- parametric surface with vectorial dimensioning and tolerancing (VD\&T) strategy $[7,8]$.

\section{Discrete shape}

The skin model is imagined as a continuous surface. To be integrated in computer systems, the skin model could be simplified to obtain a finite description like a discrete shape. In this case, the real tooth surface $\Sigma$ is represented by a set of points which are defined in a global coordinate system $\mathrm{S}_{\mathrm{f}}$. 
$\left\{\begin{array}{l}\Sigma_{f}^{(1)}\left(\phi_{1}\right)=M_{f 1}\left(\phi_{1}\right) \cdot \Sigma_{1}^{(1)} \\ \Sigma_{f}^{(2)}\left(\phi_{2}\right)=M_{f 2}\left(\phi_{2}\right) \cdot \Sigma_{2}^{(2)}\end{array}\right.$

With

$\Sigma_{1}{ }^{(1)}, \Sigma_{2}{ }^{(2)}$ : set of points of the skin model in the local coordinate system.

$M_{f 1}$ and $M_{f 2}$ : transform matrices from skin model coordinate system to the global coordinate system.

$\Phi_{1}$ is rotational angle of pinion 1 and $\Phi_{2}$ is rotational angle of wheel 2 .

To define the discrete skin model, the nominal model is sampled into a set of points (Figure 1), and the real geometry is apprehended by the displacement each point, leading to a huge number of parameters.

Fig. 1. Discrete shape illustration

\section{Discrete shape with Vectorial dimensioning and tolerancing (VD\&T) for gear}

The discrete representation $\Sigma_{7}$ is described by its model in the local coordinate system ( $S_{7}$ first substitute surface pinion 1 or $S_{8}$ first substitute surface wheel 2$)$. The model of the gear box with geometrical variations can be simulated by changing the settings and orientations of the coordinate systems (Fig. 2). Few coordinate systems $\left(\mathrm{S}_{7}\right.$,

$S_{5}, S_{3}, S_{1}$ for pinion 1 and $S_{8}, S_{6}, S_{4}, S_{2}$ for wheel 2) are introduced. They allow to parameterize geometrical deviations, gaps and displacements: error on cumulative angular pitch, position and orientation deviations between the axis of the teeth and the 
hole axis, rotational parameter, misalignments ... Therefore, we can define the model of tooth surface $\Sigma_{\mathrm{f}}$ in the global coordinate system $\mathrm{S}_{\mathrm{f}}$ (equation 2)

Fig. 2. Definition of coordinate systems of VD\&T.

$$
\left\{\begin{array}{l}
\Sigma_{f}^{(1)}\left(\phi_{1}\right)=M_{f 1} \cdot M_{13}\left(\phi_{1}\right) \cdot M_{35} \cdot M_{57} \cdot \Sigma_{7}^{(1)} \\
\Sigma_{f}^{(2)}\left(\phi_{2}\right)=M_{f 2} \cdot M_{24}\left(\phi_{2}\right) \cdot M_{46} \cdot M_{68} \cdot \Sigma_{8}^{(2)}
\end{array}\right.
$$

With

$M_{i j}$ is the transform matrix from $S_{j}$ to $S_{i}$.

The standardized situation deviations [9], [10] are coherent with this model:

- the situation deviations between flanks,

- Cumulative pitch deviation $\mathrm{F}_{\mathrm{pk}}$ over a sector of $\mathrm{k}$ pitches: algebraic difference between the actual length and the theoretical length of the relevant arc. It is equal to the algebraic sum of the single pitch deviations of the same $k$ pitches.

- Single pitch deviation $f_{p t}$, Mean base pitch deviation $f_{p b m}, \ldots$

- the situation deviations between teeth and hole.

- Runout of teeth, $\mathrm{F}_{\mathrm{r}}$ : total variation of the distance between a datum surface(s) (hole) and an indicated surface(s) (teeth).

O Eccentricity $f_{e}\left(f_{e L}, f_{e R}\right)$, Wobble $F_{s}\left(F_{s L}, F_{s R}\right), \ldots$

And the form deviations are described with the parameterization of the discrete shape:

- the flank deviations (profile or form deviations), 
- Total profile deviation $F_{\alpha}$ : distance between two design profiles which enclose the actual profile over the evaluation range $L_{\alpha}$, subject to provisions of the above.

- Profile form deviation $f_{f \alpha}$, Profile slope deviation $f_{H \alpha}, \ldots$

\section{Parametric surface and Parametric surface with VD\&T}

The substitute skin model $\Sigma$ is described by its parametric model in the global or local coordinate system. The definition of its parametric model is decomposed into 3 steps: the definition of the nominal surface, the addition of the crowning and the addition of the deviations:

Substitute tooth surface model $=$ Nominal tooth surface model + Crowning + deviations

Form deviations can be defined by the deviations between the substitute tooth profile and theoretical profile (Nominal tooth surface model + Crowning). For each point of each tooth surface, this deviation is the displacement normal to profile of this point:

$w^{(1), j}\left(u_{1}, v_{1}\right) \cdot \mathbf{n}_{7}^{(1)} \quad$ or $\quad w^{(2), k}\left(u_{2}, v_{2}\right) \cdot \mathbf{n}_{8}^{(2)}$

With

$\mathrm{j} \in\left\{0, \ldots, \mathrm{Z}_{1}-1\right\}$ and $\mathrm{k} \in\left\{0, \ldots, \mathrm{Z}_{2}-1\right\}$ : tooth index

$w^{(1), j}\left(u_{1}, v_{1}\right)$ : deviation parametric expression of the tooth $j$.

To describe the form deviations as these parametric functions, we can find lots of solutions, such as the famous Fourier transform applied to roughness filtering, the 
Discrete Cosinus Transform (DCT) [11] proposed by Huang and Ceglarek, and the modal tolerancing proposed by Samper et al [12], which is a generic approach that is able to describe form deviations of any geometry.

In the case of the parametric surface, skin model representation of teeth surfaces in the global coordinate system is given by:

$$
\begin{aligned}
& S_{f}^{(1), j}\left(u_{1}, v_{1}, \Phi_{1}\right)= \\
& \quad M_{f 1}\left(\Phi_{1}\right) \cdot\left(S_{1}^{(1)}\left(u_{1}, v_{1}\right)+w_{1}^{(1), j}\left(u_{1}, v_{1}\right) \mathbf{n}_{1}^{(1)}\right) \\
& S_{f}^{(2), k}\left(u_{2}, v_{2}, \Phi_{2}\right)= \\
& \quad M_{f 2}\left(\Phi_{2}\right) \cdot\left(S_{2}^{(2)}\left(u_{2}, v_{2}\right)+w_{2}^{(2), k}\left(u_{2}, v_{2}\right) \cdot \mathbf{n}_{2}^{(2)}\right)
\end{aligned}
$$

With

$$
S_{1}^{(1)}\left(u_{1}, v_{1}\right), S_{2}^{(2)}\left(u_{2}, v_{2}\right) \text { : Nominal parametric expression. }
$$

In the case of the parametric surface with VD\&T coordinate systems decomposition, skin model representation of teeth surfaces in the global coordinate system is given by:

$$
\begin{gathered}
S_{f}^{(1), j}\left(u_{1}, v_{1}, \Phi_{1}\right)=M_{f 1} \cdot M_{13}\left(\phi_{1}\right) \cdot M_{35} \cdot M_{57} \\
.\left(S_{1}^{(1)}\left(u_{1}, v_{1}\right)+w_{1}^{(1), j}\left(u_{1}, v_{1}\right) \cdot \mathbf{n}_{1}^{(1)}\right) \\
S_{f}^{(2), k}\left(u_{2}, v_{2}, \Phi_{2}\right)=M_{f 2} \cdot M_{24}\left(\phi_{2}\right) \cdot M_{46} \cdot M_{68} \\
.\left(S_{2}^{(2)}\left(u_{2}, v_{2}\right)+w_{2}^{(2), k}\left(u_{2}, v_{2}\right) \cdot \mathbf{n}_{2}^{(2)}\right)
\end{gathered}
$$

As the discrete shape with the proposed VD\&T, the parametric surface with proposed VD\&T is coherent with the standardized deviations [8].

\section{TOOTH CONTACT ANALYSIS TECHNIQUES}

The aim of TCA is to obtain the real gear ratio at the mean contact point during the meshing, contact path, orientation and size of contact ellipse. Only the first one is evaluated in this study. If the teeth surfaces and the relative positions are perfect, the 
instantaneous gear ratio would be constant. Due to misalignment and parts deviations, this instantaneous kinematic relationship is changing [7]. The relative variations of real gear ratio are minor but accelerations induced are not negligible. Indeed, jump of angular velocity must be avoided in order to reduce noise level and vibrations [13].

\section{TCA for discrete shape}

The aim of TCA is to determine the relationship between the two rotational angles $\left(\Phi_{1}\right.$ and $\left.\Phi_{2}\right)$. To do so, it is necessary to traduce the contact between the two teeth surfaces. In the case of discrete shape, the condition of contact between the two surfaces (Fig. 3) is given by:

$\operatorname{Min}\left(e\left(M_{i}\right)\right)_{M_{i} \in \Sigma^{(1)}}=0$

with

$e\left(M_{i}\right)=M_{i} M_{p} \cdot \mathbf{n}_{\mathbf{i}}$

$M_{p} \in \Sigma^{(2)}, \quad\left\|M_{i} M_{p} \wedge \mathbf{n}_{\mathbf{i}}\right\|=0$

Fig. 3. Teeth gap in the case of discrete shape

Numerical methods are required to identify the contact point for each

configuration of the pinion 1 . To simplify this numerical resolution, we can simplify the model: we consider the contact point in the meshing plan PI. The new condition of contact between the two surfaces (Fig. 4) is given by: 
$\operatorname{Min}\left(e\left(P\left[M_{i}\right]\right)\right)_{M_{i} \in \Sigma^{(1)}}=0$

with

$P\left[M_{i}\right]$ is the projection of $M_{i}$ in $P l$

$e\left(P\left[M_{i}\right]\right)=P\left[M_{i}\right] P\left[M_{p}\right] \cdot \mathbf{n}$

$M_{p} \in \Sigma^{(2)}, \quad\left\|P\left[M_{i}\right] P\left[M_{p}\right] \wedge \mathbf{n}\right\|=0$

This mathematical problem does not have an explicit solution in the general

case. We may only have an approximate numerical solution. With this aim, the following method is used:

- to choose a series of values for $\Phi 1$,

- for each value of $\Phi 1$, to solve the optimization problem which is made by an iterative method,

- to analyze the instantaneous kinematics error.

This tooth contact analysis allows to define the kinematic relationship during the meshing of one tooth. To define it during the global meshing, we reproduce this analysis for each tooth which is nominally in contact, we obtain each kinematic relationship of each tooth, and we calculate the superior (or inferior, that depends on the direction of rotation) envelope of these relationships.

Fig. 4. Projected teeth gap in the case of discrete shape

\section{TCA for parametric surface}

During the meshing, surfaces $S^{(1)}$ and $S^{(2)}$ are tangential (Fig. 5) and it is well known the necessary and sufficient conditions for this situation are [14]: 


$$
\left\{\begin{array}{l}
S_{f}^{(1)}\left(u_{1}, v_{1}, n, \Phi_{1}\right)=S_{f}^{(2)}\left(u_{2}, v_{2}, m, \Phi_{2}\right) \\
N_{f}^{(1)}\left(u_{1}, v_{1}, n, \Phi_{1}\right)=c \cdot N_{f}^{(2)}\left(u_{2}, v_{2}, m, \Phi_{2}\right) \\
\left(u_{1}, v_{1}\right) \in[0,1]^{2} \\
\left(u_{2}, v_{2}\right) \in[0,1]^{2} \\
\left(\phi_{1}, \phi_{2}\right) \in R^{2} \\
c \in \mathrm{R}
\end{array}\right.
$$

Fig. 5. Contact condition in the case of parametric surface

The most difficult in TCA is to solve a system of non-linear equations that traduce contact between the two surfaces. When the position of contact point(s) is (are) known, it's easy to determinate the real gear ratio and transmission error, the contact paths on the gear tooth surfaces. Like the TCA for discrete shape, numerical methods are required, iterative methods are used.

These three TCA approaches have been implemented and tested in a case of a meshing of two gears. The algorithm is chosen as a function of its rapidity and precision. The following table shows the results for a simulation (20 turns with 60 angular positions for each tooth).

Table 1. A comparison between the different approaches. 
To compare a numerical result and an experimental result, the data points of the measured gears are used as input of the meshing simulation program. Meshing results are then compared with real meshing measurement on meshing machine (Fig 6).

Fig. 6. Comparison between measurements and simulation.

As shown, a great similarity is obtained. The differences could be due to the measurement uncertainties and the geometrical variations of the master gear and the assembly for the kinematic simulation; in fact, the numerous meshing simulations don't take into account the geometrical variations of the master gear.

\section{COMPARISONS OF THESE MODELS \& CONCLUSION}

We proposed four skin model representations of gear and three techniques for Tooth Contact Analysis. To compare them, the chosen criteria are:

- The compatibility between them,

- The adequacy with the metrology or standard practices,

- The accuracy of the simulation,

- $\quad$ The computing time.

The comparison results are shown in the tables $2,3,4$ and 5.

Table 2. Compatibility 
Parametric surfaces are continuous, and they offer the convenience that discrete shape can be enumerated very quickly by simply choosing coordinates in the parameter space. Therefore, TCA for discrete shape can be used easily with a skin model which is represented by parametric surfaces.

Table 3. Adequacy with the metrology or standard practices

The skin model representation with VD\&T is coherent with the standard and metrology practices. The important point of the proposed skin model representations for gear is to provide an unique solution to express tolerances based on geometry. Taken into account directly, in the expression of the specification, the result based on a mathematical expression is unique and clearly described for everybody. There is no more interpretation for the designer, the manufacturer and the metrologist.

Table 4. Accuracy of the simulation

By all approaches, accurate numerical simulations are performed to obtain transmission error.

Table 5. Computing time

The technique based on the projection is a fast solution. 
The discrete shape with VD\&T and the TCA approach based on the projection offers the best compromise between the accuracy, the computing time and the adequacy with the standard practice.

\section{ACKNOWLEDGMENT}

The author would like to acknowledge the support of ANR "AHTOLA" project (ANR-11MONU-013).

The author is thankful to Dr Jean-Paul VINCENT, Ms Eric RAVEANE, Marie ETIENNE \& Eglantine KUNLE for their contributions (implementation \& metrology). FUNDING A separate section listing funding sources should be included. The full names along with their abbreviation should be included, e.g., U.S. Department of Energy (DOE). 


\section{REFERENCES}

(Samples of the most commonly referenced materials are provided. If in doubt, please refer to the latest editor of the Chicago Manual of Style. DOls should be provided whenever possible for the greatest accuracy.

[1] Loucks, D., 2003, "Quantifying and Communicating Model Uncertainty for Decisionmaking in the Everglades". Risk-Based Decisionmaking in Water Resources X: pp. 40-58. doi: 10.1061/40694(2003)4.

[2] Ballu A, Mathieu L, 1993, "Analysis of Dimensional and Geometrical Specifications: Standards and Models". Proc. 3rd CIRP Seminar on Computer Aided Tolerancing, Cachan, France.

[3] Zhang M, Anwer N, Stockinger A, Mathieu L, Wartzack S, 2012. “Discrete Shape Modeling for Skin Model Representation". 12th CIRP Conference on Computer Aided Tolerancing, Huddersfield, UK.

[4] Schleich B, Anwer N, Mathieu L, Walter M, Wartzack S, 2012. "A Comprehensive Framework for Skin Model Simulation". Proceedings of the ASME 11th Biennial Conference on Engineering Systems Design and Analysis, Nantes, France.

[5] Requicha A.A.G., 1993. "Mathematical Meaning and Computational Representation of Tolerance Specifications". International Forum on Dimensional Tolerancing and Metrology, CRTD-Vol. 27, pp. 61-68.

[6] Wirtz A., 1991. "Vectorial tolerancing for production quality control and functional analysis in design". Annals of CIRP, Pennstate, USA.

[7] Bruyere J., Dantan J.Y., Bigot R., Martin P., 2007. "Statistical tolerance analysis of bevel gear by Tooth Contact Analysis and Monte Carlo Simulation". Mechanism and Machine Theory, Vol. 42, n¹0, pp. 1326-1351.

[8] Dantan J.Y., Bruyere J., Baudouin C., Mathieu L., 2007. "Geometrical specification for gear-Expression, metrology and analysis". Annals of the CIRP, Vol. 56, pp517-520.

[9] Goch G., 2003. "Gear metrology". Annals of the CIRP, Vol.52, pp. 659-695.

[10] Guenther A., 2006. "Evaluation of runout deviation at bevel gears based on pitch measurements". Annals of the CIRP, Vol. 55, pp. 539-542.

[11] Wenzhen H., Ceglarek D., 2002. "Mode-based Decomposition of Part Form Error by Discrete-Cosine-Transform with Implementation to Assembly and Stamping System with Compliant Parts". Annals of the CIRP, Vol.51, pp. 21-26. 
[12] Grandjean J., Ledoux Y., Samper S., Favrelière H., 2013. “Form Errors Impact in a Rotating Plane Surface Assembly". Procedia CIRP, Vol. 10, pp. 178-185.

[13] Litvin F.L.,2004. "Gear Geometry and Applied Theory". PTR Prentice Hall, Englewood Cliffs, NJ.

[14] Vincent J.P., Dantan J.Y., Bigot R., 2009. "Virtual meshing simulation for gear conformity verification". CIRP Journal of Manufacturing Science and Technology, Vol.2, $\mathrm{n}^{\circ} 1$, pp. 35-46. 


\section{Figure Captions List}

Fig. 1 Discrete shape illustration

Fig. 2 Definition of coordinate systems of VD\&T.

Fig. 3 Teeth gap in the case of discrete shape

Fig. $4 \quad$ Projected teeth gap in the case of discrete shape

Fig. 5 Contact condition in the case of parametric surface

Fig. 6 Comparison between measurements and simulation 


\section{Table Caption List}

Table 1 A comparison between the different approaches.

Table 2 Compatibility

Table 3 Adequacy with the metrology or standard practices

Table $4 \quad$ Accuracy of the simulation

Table 5 Computing time 
Figure 1

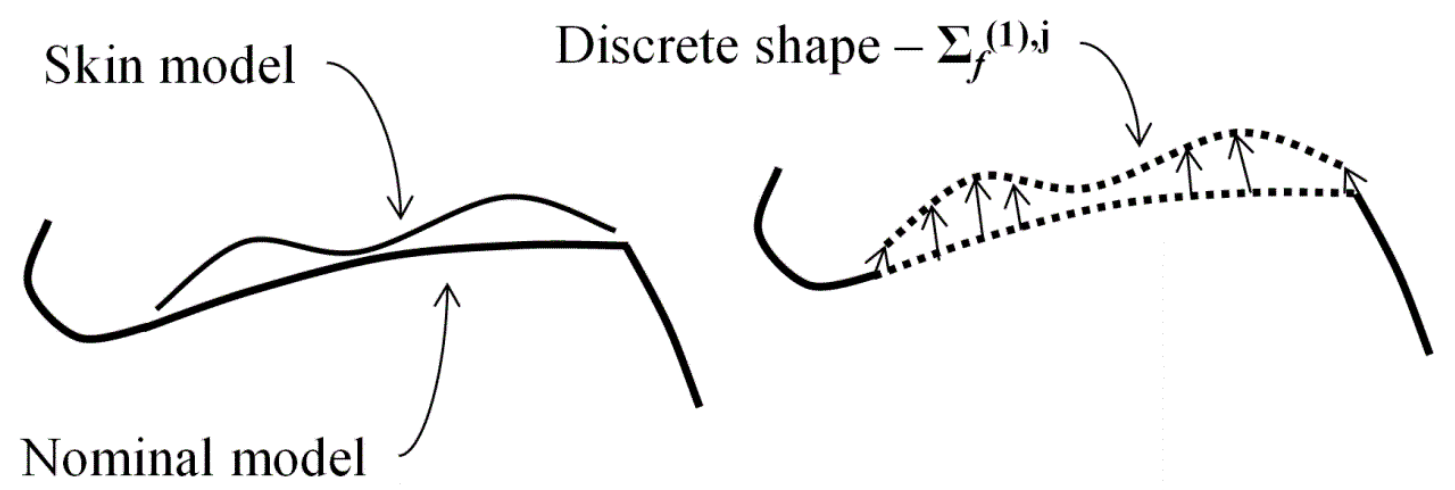




\section{Figure 2}

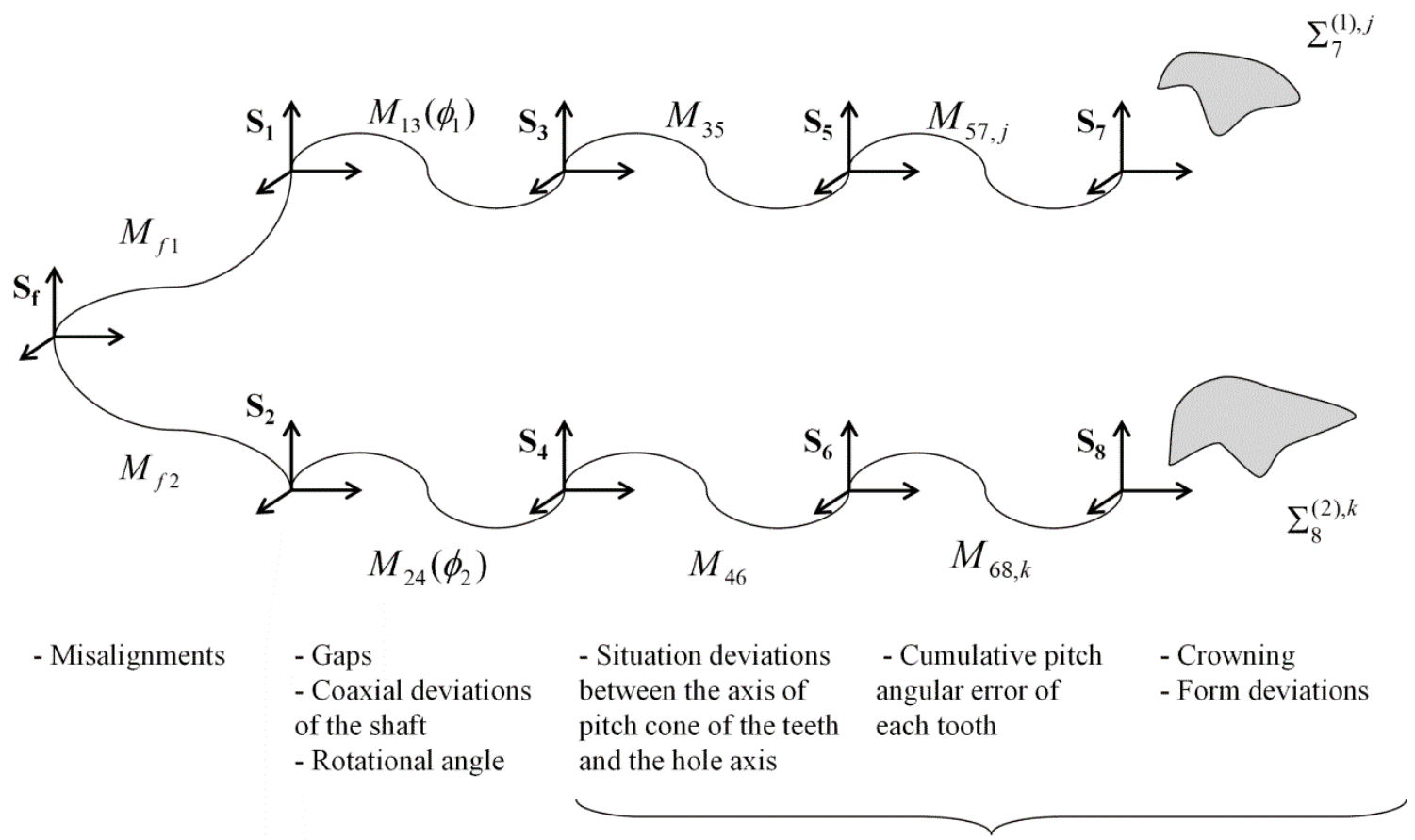

Pinion deviations and wheel deviations 
Figure 3

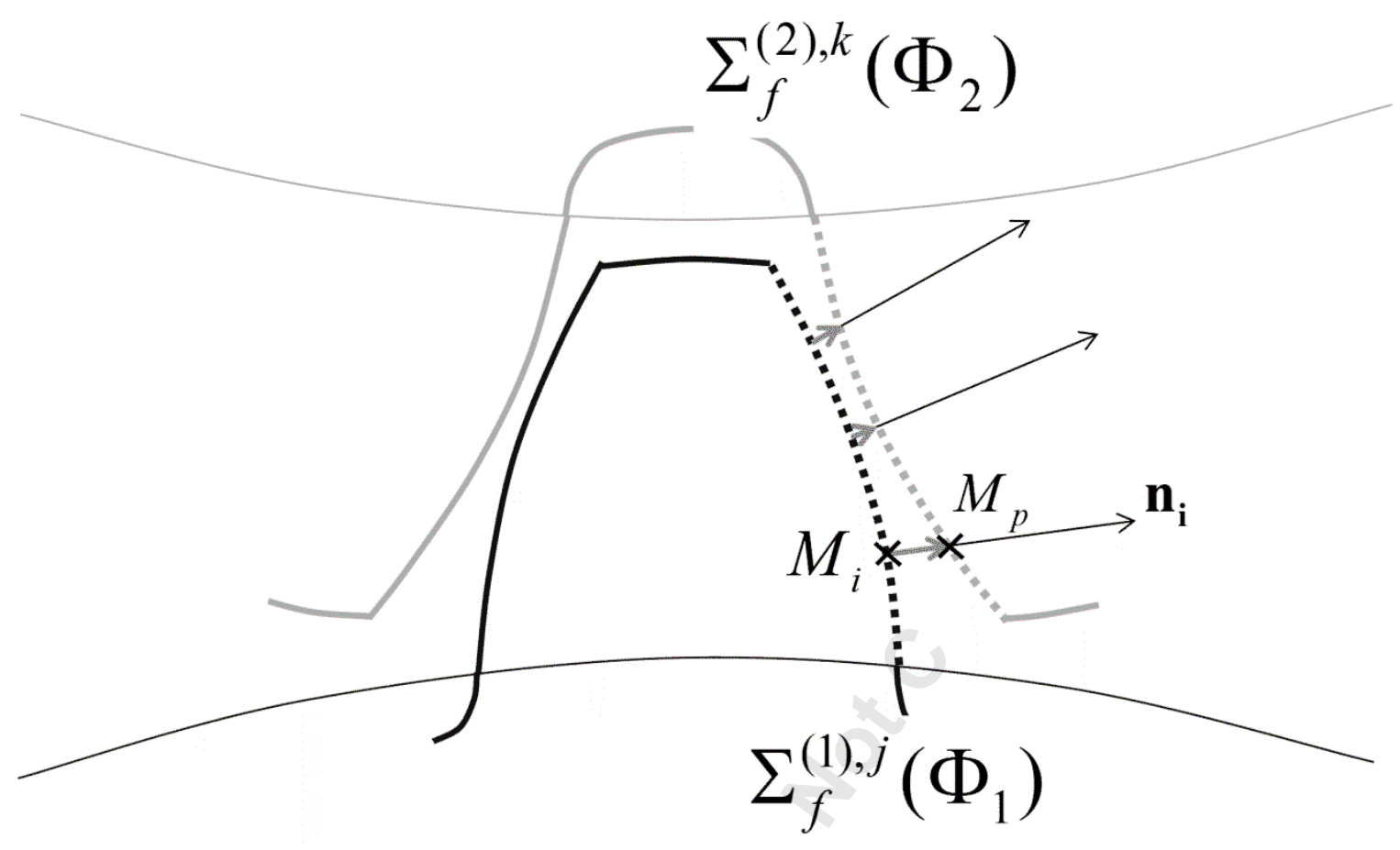


Figure 4

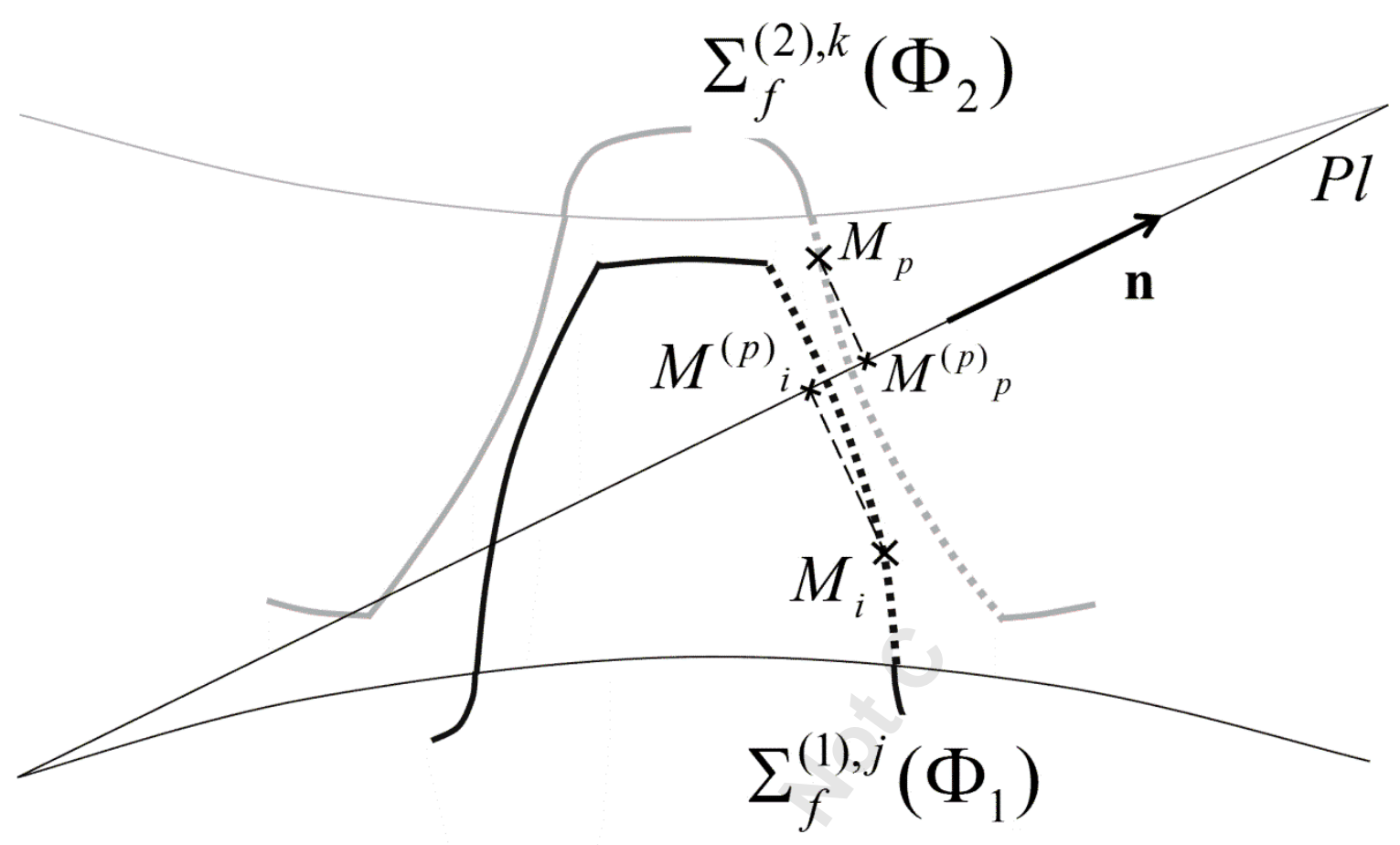


Figure 5

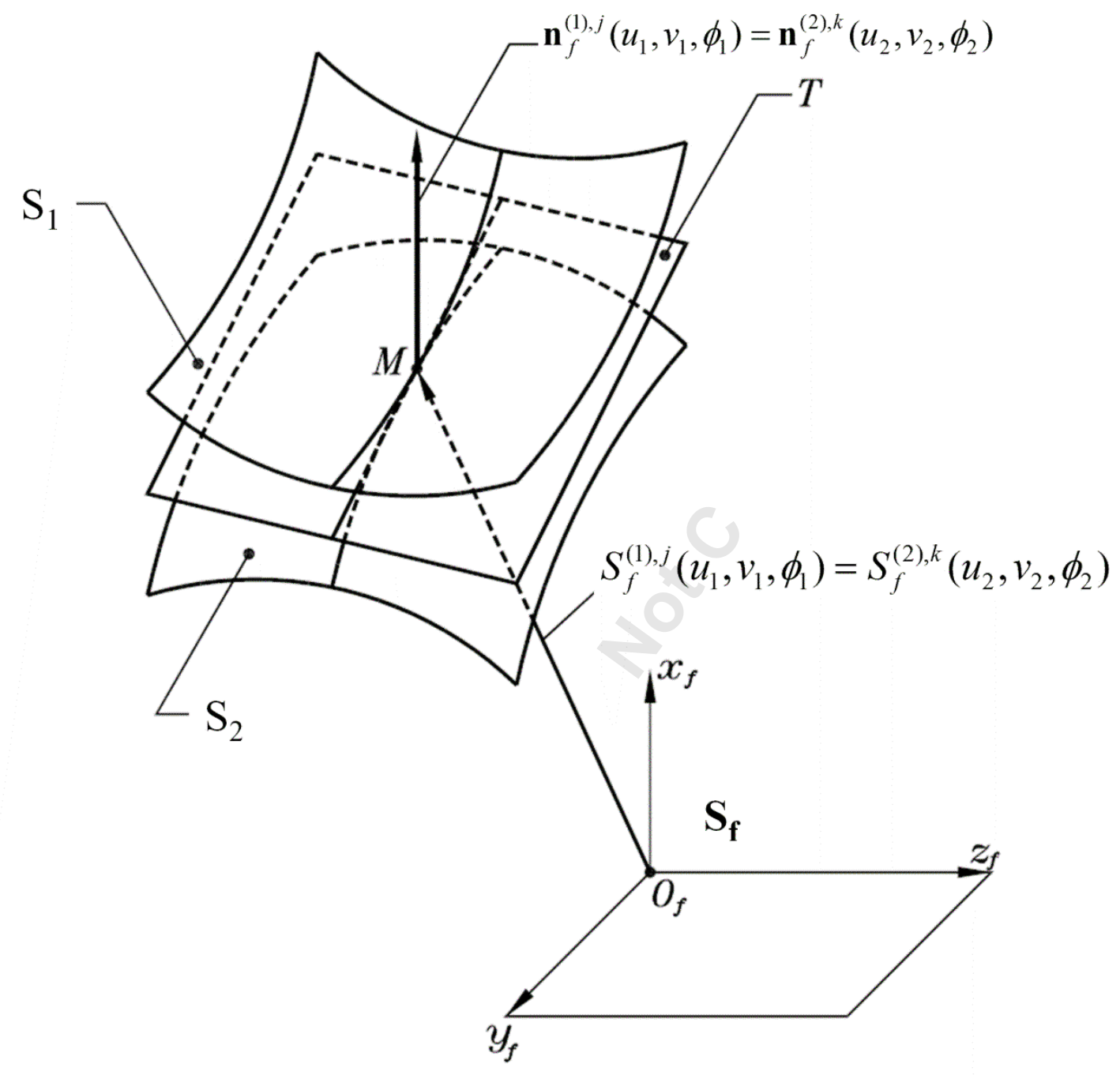


Figure 6

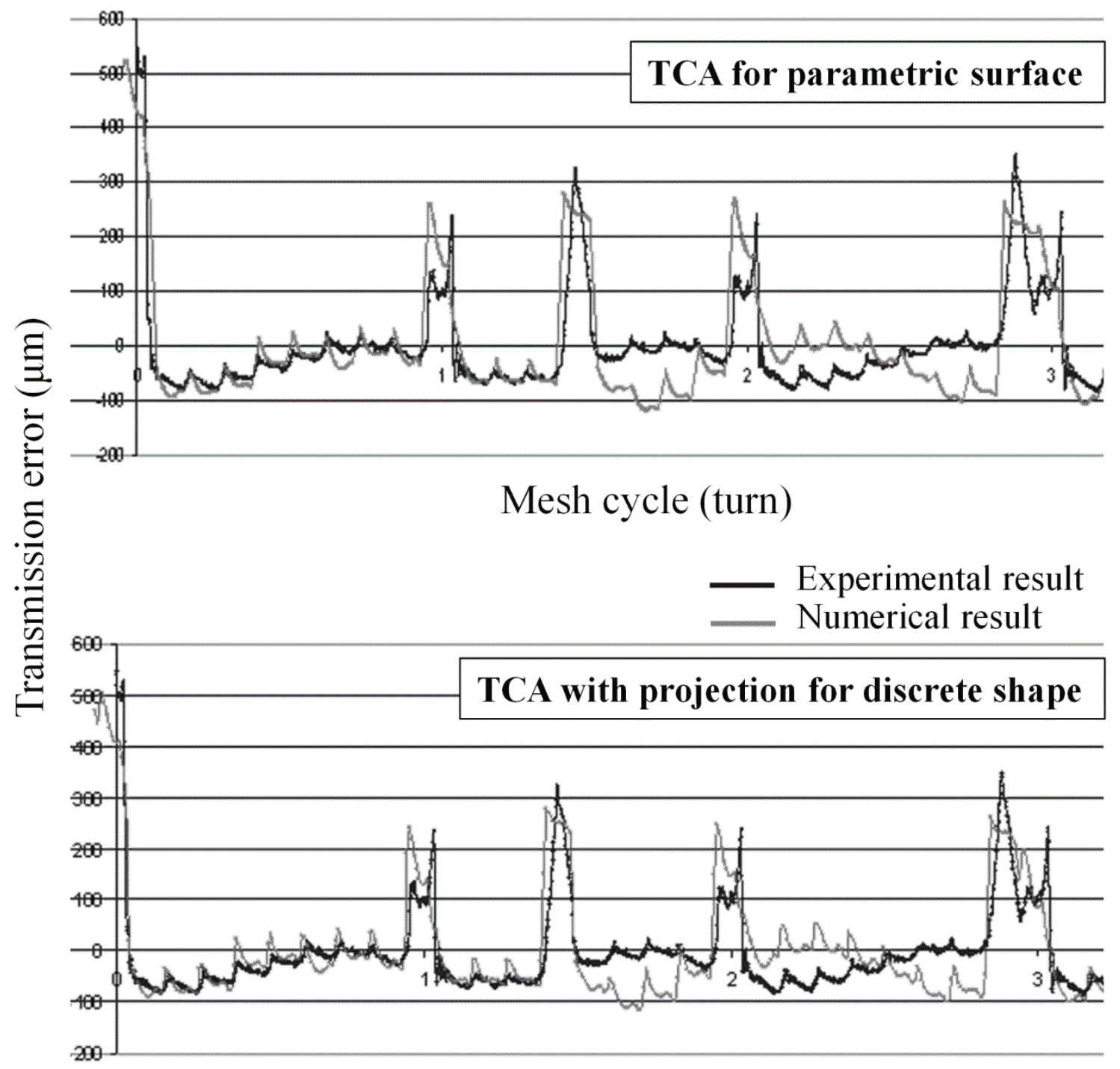


Table 1. A comparison between the different approaches.

\begin{tabular}{|l|l|l|}
\hline & $\begin{array}{l}\text { Average time calcultation } \\
\text { (minutes) }\end{array}$ & Average residual \\
\hline TCA for discrete shape & $117^{\prime}$ & $2.10-8 \mathrm{~m}$ \\
\hline $\begin{array}{l}\text { TCA with projection for } \\
\text { discrete shape }\end{array}$ & $5^{\prime}$ & $5.10-7 \mathrm{~m}$ \\
\hline $\begin{array}{l}\text { TCA for parametric } \\
\text { shape }\end{array}$ & $91^{\prime}$ & $3.10-8 \mathrm{~m}$ \\
\hline
\end{tabular}


Table 2. Compatibility

\begin{tabular}{|c|c|c|c|c|}
\hline & Discrete shape & $\begin{array}{l}\text { Discrete shape } \\
\text { with VD\&T }\end{array}$ & $\begin{array}{l}\text { Parametric } \\
\text { surface }\end{array}$ & $\begin{array}{l}\text { Parametric } \\
\text { surface with } \\
\text { VD\&T }\end{array}$ \\
\hline $\begin{array}{l}\text { TCA for discrete } \\
\text { shape }\end{array}$ & OK & OK & $\begin{array}{l}\text { Need a } \\
\text { discretization } \\
\text { operation }\end{array}$ & $\begin{array}{l}\text { Need a } \\
\text { discretization } \\
\text { operation }\end{array}$ \\
\hline $\begin{array}{l}\text { TCA with } \\
\text { projection for } \\
\text { discrete shape }\end{array}$ & OK & OK & $\begin{array}{l}\text { Need a } \\
\text { discretization } \\
\text { operation }\end{array}$ & $\begin{array}{l}\text { Need a } \\
\text { discretization } \\
\text { operation }\end{array}$ \\
\hline $\begin{array}{l}\text { TCA for } \\
\text { parametric } \\
\text { surface }\end{array}$ & $\begin{array}{l}\text { Need a fitting } \\
\text { operation }\end{array}$ & $\begin{array}{l}\text { Need a fitting } \\
\text { operation }\end{array}$ & OK & OK \\
\hline
\end{tabular}


Table 3. Adequacy with the metrology or standard practices

\begin{tabular}{|l|c|c|c|c|}
\hline & Discrete shape & $\begin{array}{c}\text { Discrete shape } \\
\text { with VD\&T }\end{array}$ & $\begin{array}{c}\text { Parametric } \\
\text { surface }\end{array}$ & $\begin{array}{c}\text { Parametric } \\
\text { surface with } \\
\text { VD\&T }\end{array}$ \\
\hline Adequacy & -- & ++ & -- & ++ \\
\hline
\end{tabular}


Table 4. Accuracy of the simulation

\begin{tabular}{|l|c|}
\hline & Accuracy \\
\hline TCA for discrete shape & +++ \\
\hline TCA with projection for discrete shape & ++ \\
\hline TCA for parametric shape & +++ \\
\hline
\end{tabular}


Table 5. Computing time

\begin{tabular}{|l|c|}
\hline & Computing time \\
\hline TCA for discrete shape & - \\
\hline TCA with projection for discrete shape & +++ \\
\hline TCA for parametric shape & - \\
\hline
\end{tabular}

